\title{
Formação ética de professores: a contribuição de Edgar Morin
}

\author{
Solange Martins Oliveira Magalhães*
}

\section{Resumo}

A presença da ética na formação de professores é um fator essencial no processo de humanização. Essa ideia expressa uma direção contrária à atual proposta de políticas educacionais que atualmente apóia a formação de professores sob uma perspectiva técnica e instrumental. Perspectiva que reduz a função social dos professores na preparação da conduta humana, particularmente a que visa a participação colaborativa e solidária. A perspectiva complexa relaciona a ética da humanidade à melhoria da humanidade, é aqui apresentada como uma possibilidade de proporcionar aos futuros professores a oportunidade de compor uma "nova base" de valores que expandam a ética, visando a abertura altruísta entre os sujeitos. Palavras-chave: Formação de professores; Ética; Ética complexa.

\section{Ethical training of teachers: Edgar Morin's contribution}

\section{Abstract}

The presence of ethics in teacher education is an essential factor in the humanization process. This idea expresses a direction contrary to the current proposal for educational policies that currently supports teacher training from a technical and instrumental perspective. Perspective that reduces the social function of teachers in the preparation of human conduct, particularly that aimed at collaborative and solidary participation. The complex perspective relates the ethics of humanity to the improvement of humanity, it is presented here as a possibility to provide future teachers with the opportunity to compose a "new basis" of values that expand ethics, aiming at the altruistic opening between subjects.

Key words: Teacher training; Ethics; Complex ethics.

Doutora em Educação pela Universidade Federal de Goiás - UFG e professora do PPGE na UFG. solufg@hotmail.com 


\section{Formación ética de profesores: contribución de Edgar Morin}

\section{Resumen}

La presencia de la ética en la formación docente es un factor esencial en el proceso de humanización. Esta idea expresa una dirección contraria a la propuesta actual de políticas educativas que actualmente apoya la formación del profesorado desde una perspectiva técnica e instrumental. Perspectiva que reduce la función social de los docentes en la preparación de la conducta humana, particularmente la dirigida a la participación solidaria y colaborativa. La perspectiva compleja relaciona la ética de la humanidad con la mejora de la humanidad, se presenta aquí como una posibilidad para proporcionar a los futuros maestros la oportunidad de componer una "nueva base" de valores que expandan la ética, con el objetivo de la apertura altruista entre las asignaturas.

Palabras clave: Formación docente; Ética; Ética compleja.

\section{Introdução}

Reafirmar a importância da relação entre a formação e o processo de humanização, num direcionamento contrário à atual proposta das políticas educativas, que assume a formação docente, por exemplo, como mera formação técnica e instrumental, amplia o sentido ético da educação. Ao mesmo tempo, esse posicionamento dá novo sentido à discussão sobre as possibilidades da formação ética dos professores, ampliando a importância de sua função social na preparação da conduta humana, particularmente daquela voltada à participação colaborativa e solidária dos sujeitos.

Em termos gerais, a formação dos professores passa por conhecimentos teóricos, técnicos e éticos, dentre outros, o que deveria ordenar a construção de uma consciência profissional, política e ética. Entretanto, em função das atuais deliberações neoliberais e as alterações impostas ao campo da formação docente, como aligeiramento, formação via EAD, baixa qualidade dos cursos -, o processo não tem efetivado entre os professores a capacidade básica de analisar criticamente os projetos educacionais, no sentido de redescobrir novos caminhos para lidar com os desafios da educação em nossa época. 
A formação ética permeia e demarca as possibilidades de os professores serem capazes de entender os sentidos postos ao processo educativo. Afinal, a educação está relacionada a um projeto de sociedade, cujas finalidades e valores sempre estão diretamente associados a um programa político e moral que alteram não só a sua prática educativa, mas também a construção da cidadania, da consciência moral no cenário de um mundo globalizado.

No atual projeto de educação, portanto de sociedade, a formação ética dos professores também ganha centralidade por estar relaciona à formação moral ${ }^{1}$ dos estudantes, à formação de sua consciência crítica, de seus ideais de liberdade e cidadania. A tomada de consciência dos sujeitos de pertencimento ao grupo, como parte integradora e importante do tecido social, passa necessariamente pela educação, logo pela ação dos professores (SEVERINO, 2011)

Diante dos problemas atuais, "outra consciência" exige uma educação esteja comprometida com a formação ética dos professores e a despeito de ser uma dificultosa questão, é um caminho de diálogo que encontra na perspectiva complexa, ou na ética do gênero humano, um meio de aprimoramento da humanidade (MORIN, 2007).

Essa ideia aloja o professor e sua prática no centro da discussão que passa pelo entendimento: 1) do papel da ética na individuação dos sujeitos; 2) da compreensão dos valores que os professores cultuam, ensinam, constroem com os seus estudantes; 3) da contribuição da ética complexa na formação ética de professores. A conclusão sustenta a ética complexa como intensificadora do processo de humanização. Os três motes fundamentais do texto, aqui referidos, trazem em seu bojo a crença com relação às efetivas contribuições da teoria da complexidade ao processo de formação ética dos professores, essa seria uma opção que pode ajudar a consolidar

A moral significa originariamente costume, conjunto de valores, regras e princípios de conduta, admitido e aceito por um determinado grupo social com a finalidade de organizar as relações entre as pessoas. Sua principal função é desenvolver uma matriz axiológica que oriente as práticas sociais tornando as relações mais humanizadas entre os homens. (VÁZQUEZ, 2006) 
a ancoragem em valores éticos de respeito à dignidade humana e sincero empenho na construção de uma sociedade onde todos possam viver com dignidade (PADILHA; LEONI, 2017, p.89).

\section{O que os professores em formação ética devem entender? A ética e a individuação dos sujeitos}

Os professores podem criar um entorno social em que os estudantes assumam por si mesmos, as responsabilidades de uma vida moral democrática?

No nosso entender, dependendo da formação recebida os professores podem promover ações correlatas à práxis, portanto transformadoras, o que influenciara incisivamente na formação da capacidade dos sujeitos de emitir juízos de valor melhor elaborados. Conforme afirmou Guzzo (2011), o processo ensino-aprendizagem legitima as relações sociais e ao introduzir e garantir ao sujeito aspectos da ética pode ajudar nos processos de individuação, no senso coletivo e crítico, consequentemente, na definição de ações éticas e humanizadora entre os sujeitos (PADILHA; LEONI, 2017).

Afinal, a formação ética dos professores os torna capazes de influir na individuação dos estudantes, sendo agentes na consolidação da autonomia. O processo suscita elementos da ética como agentes de uma visão crítica e consciente da realidade e, da mesma forma como afirmou Freire, os professores podem substituir a educação "bancária" por uma ação democrática nas suas salas de aula, a partir de ações de esclarecimentos de si e do outro, de respeito, sempre vendo o estudante na sua singularidade,

[...] ao mesmo tempo em que a ele se reivindica a capacidade de operar no lugar do outro, todos se entendendo segundo o regramento ético-politico da vida em sociedade instituído para o bem viver em coletividade: não massificado e obediente passivo em relação às regras nem alienado dos sentidos construídos pela coletividade da qual faz parte, mas operando com consciência sobre o "lugar" que nela ocupa. (MARQUES, 2006, p. 
Considerando o relatado de Marques (2006), a individuação dos sujeitos exige uma educação integral, transdisciplinar, complexa, cuja finalidade é a constituição da autoconsciência crítica, moralmente determinada pela ética. Os aspectos ético e moral da educação entrelaçam os parâmetros e normatização dos princípios democráticos que favorecem o cruzamento do comprometimento dos estudantes pelo destino político da sociedade.

Portanto, a formação ética é fundamental nos processos de individuação dos sujeitos, na busca da humanidade e, no caso dos professores, explicita o seu papel decisivo, bem como da escola, na formação do caráter dos sujeitos. Afinal, numa perspectiva de educação para a promoção humana, portanto complexa, torna-se imprescindível à valorização das qualidades humanas, o que envolve o pensamento, os sentimentos, as crenças, a sensibilidade, totalmente entrelaçadas a valoração, responsabilidade, autonomia, autoridade e política, justamente por não abrir mão da ética.

\section{A formação ética deve fazer entender aos docen- tes a importância dos valores que cultuam, ensi- nam, constroem com os seus estudantes}

Em meio ao turbilhão de incertezas e contradições impostas pela sociedade contemporânea, enfrentamos um processo social conflituoso e perverso que indubitavelmente compromete o processo de individuação dos sujeitos. Infelizmente, a consciência do eu torna-se mais importante que a consciência coletiva, tendo como uma de suas principais causas o distanciamento da construção de uma identidade ética.

Quem não concorda que no bojo do cenário ético contemporâneo, somente a educação pode ser prática interventiva capaz de atingir diretamente os sujeitos e, como tal, pode e deve ter como princípio básico - a ética? Como afirmamos, a educação pode gestar sujeitos preocupados com os problemas sociais, com sua coletividade. E por ajudá-los a terem maior sensação de pertencimento social, a educação abre as possibilidades de ampliação no espaço público dos valores solidários. 
Nesse sentido, os valores que os professores cultuam, ensinam, constroem com os seus interlocutores irá ajudá-los a se posicionar frente aos apelos ambivalentes do cotidiano, orientados pelos interesses econômicos e mercadológicos do mundo globalizado. Cabe à educação, via ação docente, ajudar a formar sujeitos capazes de refletir sobre sua própria ação, mesmo entendendo que elas podem ser influenciadas por vários meios de imposições de natureza sociocultural, dos costumes, da moral do grupo e, também, a partir da livre vontade, do arbítrio (SEVERINO, 2011).

Severino (2011) aponta que a formação ética está relacionada aos modos de conceber as finalidades da educação, e embora o sujeito não seja totalmente determinado nem inteiramente livre, pois sofre influências do mundo objetivo e de sua subjetividade, seria no entrelaçamento dos valores que atravessam as relações sociais, sobretudo via educação, que os valores postos aos sujeitos resultarão em sua consciência. Logo, não se pode prescindir da formação ética dos docentes na contemporaneidade, enquanto exigência que vai além do domínio do saber teórico, envolvendo também a sensibilidade ao caráter político, habilidade técnica e envolvimento ético vinculado a um compromisso com o destino dos homens.

Severino advoga que a mediação ética revela sua complexidade na ação docente, pois além de tocar o intelecto dos estudantes, move sua vontade. Por certo que os valores que os professores professam, ensinam, repassam um sentido valorativo que pode despertar a sensibilidade ao valor da dignidade humana. Portanto, os aspectos da ambiência da formação ética dos docentes envolvem múltiplas possibilidades e acabam estruturando muito mais do que o ser professor, definem a própria complexidade do processo educativo (HARGREAVES, 1999).

Severino $(2011)$ e Rios $(2008 ; 2010)$ analisam que, em suas múltiplas relações, a dimensão ética do fazer docente é fundante da docência. Sobre as bases da ética, desde sua gênese, a docência ou o fazer docente, associa-se ao compartilhamento intra e intersubjetivo eivado de sentidos e valores, destacando a importância do 
compromisso e atenção no trabalho desenvolvido pelo professor (SEVERINO, 2011).

Os autores ainda afirmam que a dimensão da ética associa-se a outras dimensões do fazer docente, como: a técnica, a estética, a sensível e a política, as quais definem as relações que o professor estabelece no e com seu fazer. Nos termos Severino (2011) e Rios (2008; 2010), a dimensão técnica implica no domínio do conteúdo teórico da área, no seu diálogo e interlocução com os recursos, métodos e técnicas eivados de sentidos profissionais, pessoais (objetivos e subjetivos), e culturais. A dimensão estética faz relação direta com a arte e suas formas de manifestação, se vale de memórias, percepções, imagens, afetos, ideias e sensações para estabelecer vínculos cognitivos. Por meio dessa dimensão, conforme Ponce (2012) é possível conhecer fenômenos da natureza e da cultura e, também, expressar um potencial criador. A presença do conhecimento estético na formação docente aguça a imaginação, amplia as possibilidades de apreensão da forma e do conteúdo dos objetos de conhecimento, evidenciando a capacidade de fazer associações e relações. Também exercita a curiosidade e a criatividade, gerando sentimentos de reconhecimento, pertencimento e afirmação cultural. E ainda, a dimensão estética do fazer docente possibilita um conhecimento que amplia a sensibilidade de quem conhece, isto é, estimula os sujeitos a produzirem um pensamento sensível, aspecto essencial à existência humana. Complementamos com Freire (1996, p. 46) afirmando que esta dimensão está amalgamada à sensivel, ambas dizem sobre o "bem observar, bem comparar, bem intuir, bem imaginar, bem liberar a sensibilidade”.

Outra dimensão é a política que reforça que o fazer docente é prenhe de significados político, social, cultural, ideológico, econômico, morais, éticos e estéticos, que necessitam ser comprometidos com as mudanças nas práticas individuais e sociais atuais (RIOS, 2008). A dimensão política diz sobre o como o professor desenvolverá suas ações e sobre a forma como ele indaga os valores da ciência e seus usos técnicos e como isso reflete no processo ensino-aprendizagem. 
Com Severino (2011) entendemos que é na articulação dessas dimensões - estética, sensível, política e técnica que a dimensão da ética se destaca fazendo com que o professor seja capaz de cultuar, ensinar, construir diferentes valores com os estudantes, inclusive dando-lhes maior liberdade de eleição de um curso de ação, de uma lógica e posicionamento sócio político, o que, paralelamente, leva o professor e os estudantes a assumirem maior responsabilidade pessoal e profissional pelas consequências de seu proceder e pelo valor social dos resultados de seu trabalho.

Lembremos que no mesmo nível epistemológico, a formação ética do professor deve fazer entender que seria o par bipolar e complementar - ética e a moral, que amplia a possibilidade de amalgamar valores à própria Ética dos sujeitos e às práticas sociais e/ou pedagógicas. A ética relaciona-se ao modo de ser, ao caráter que orienta as relações humanas para que essas se mantenham em condições mínimas de moralidade. A ética define um conjunto de valores ou define uma matriz referencial que define a moral dos sujeitos, ou seja, o que acreditamos ser justo, bom e melhor (VÁZQUEZ, 2006).

Portanto, a formação ética do professor resgata um sistema valorativo (moral) e valores mais elevados (ética), como: nobreza de caráter, justiça, respeito entre as pessoas, honestidade, equilíbrio, bondade, solidariedade, que gradativamente acabam conformando o comportamento ético (SEVERINO, 2006; 2010). Em outras palavras, a moral pró́be todos de fazerem ao outro aquilo que não desejam que seja feito a si mesmos, proibição que se estrutura como princípio que não comporta exceção do ponto de vista ético. Portanto, a ética é a responsável pela norma crítica, frente às estruturas sociais existentes. E embora esteja sujeita a incertezas, a formação ética precisa operar nos valores que os professores cultuam, ensinam, constroem no processo educativo para possibilitar novos rumos para o destino humano.

A transcendência do que ocorre no processo de formação docente exige novas perspectivas como o aporte teórico na teoria da complexidade. Ela traz inovação via matrizes éticas e transdis- 
ciplinares, como o proposto pelo sétimo saber de Morin (2007), denominado "A ética do gênero humano". Sua essência é precisamente a de conferir aos professores, portanto à própria educação, a possibilidade de compreensão da ética do humano, de sua integralidade, enquanto parte integrante da sociedade, compreendendo-o, assim, como indivíduo/sociedade/espécie (MORIN, 2007, p.105).

\section{A formação ética dos docentes e a contribuição de Edgar Morin}

Morin (2007) relaciona a ética do gênero humano ao aprimoramento da humanidade. Como ele mesmo afirma: para alcançar uma "[...] humanização da humanidade" (MORIN, 2007, p. 106). Entretanto, a consolidação da ética do gênero humano implica na superação da visão fragmentada e cartesiana dos cursos de formação e, portanto, bastante deficitária no sentido de implantação de uma matriz ética e transdisciplinar, orientada pelo desenvolvimento do gênero humano. Para o autor, a ética do gênero humano é uma alternativa racional de superação dos atuais problemas sociais que ora nos encontramos, observação consoante com a lição dada por Delors (1998, p. 11) no livro Educação um tesouro a descobrir, quando afirmou que ante os múltiplos desafios do futuro, a "educação surge como um trunfo indispensável à humanidade na sua construção dos ideais da paz, da liberdade e da justiça social".

Morin (2007) considera que educar fomentando uma postura ético-solidária, consolidando o chamamento à responsabilidade individual e à participação social, exige mudanças no atual modelo de educação, e isso exige mudanças nos cursos de formação docente. No mesmo sentido, Nicolescu (2000) analisou que a formação docente, logo a educação, privilegia o intelecto em detrimento de outras dimensões humanas, resultando na impossibilidade de se correlacionar saberes ou conhecimentos. Trata-se de uma disjunção que é mantida pela lógica mercantil na formação de professores, oque impede o firmamento do ideal de alteridade, além de inviabilizar uma atitude transdisciplinar. A transdisciplinaridade, 
para melhor entendimento, como prefixo 'trans' indica, diz respeito àquilo que está ao mesmo tempo entre as disciplinas, através das diferentes disciplinas e além de qualquer disciplina. Seu objetivo é a compreensão do mundo presente, para o qual um dos imperativos é a unidade do conhecimento. Conforme a perspectiva transdisciplinar, o pensamento clássico não é absurdo, mas seu campo de aplicação é considerado como restrito (NICOLESCU, 2000).

A presença da ética do gênero humano nos cursos de formação docente exigiria uma postura transdisciplinar com a valorização do exercício dos valores democráticos, do respeito às diversidades, sem olvidar da compreensão do outro. Para Morin, essas seriam características que, se desenvolvidas propiciariam ao futuro professor, condições de conscientização sobre os valores necessários à convivência social, como a solidariedade e a compreensão na interação entre as pessoas, caracterizando o sentido político da convivência e da sobrevivência da espécie humana, onde as liberdades individuais implicam responsabilidade e alteridade (MORIN, 2007).

A partir de uma perspectiva transdisciplinar e complexa, seria possível uma conjunção que possibilitaria o pensamento complexo e esse, por sua vez, ajudaria na formação de um ser humano íntegro e, por conseguinte, completo, realimentando a própria ética (MORIN, 2007). Nessa lógica, o princípio da moral e da formação ética complexa depende do próprio pensamento complexo, como base para que os professores passem a considerar sua própria ação de forma autocrítica, ajudando-os a viver e agir com consciência social, ética e ecológica.

No campo da formação docente, a ética do gênero humano exige a estruturação da tríade: a epistemologia complexa (conhecimento do conhecimento), a antropologia complexa (conhecimento do humano considerando a tríade humana indivíduo-sociedade-espécie), e a ética complexa (MORIN, 2007, p. 65): a epistemologia da complexidade envolve necessariamente a redefinição do paradigma atual e sua mudança para o da complexidade. Não se pode deixar de evocar, nesta mesma ordem de ideias, que o complexo de Morin não 
se trata do que é complicado. Na sua etimologia, complexus significa o que foi tecido em conjunto.

[...] de fato, há complexidade quando elementos diferentes são inseparáveis constitutivos do todo (como o econômico, o político, o sociológico, o psicológico, o afetivo, o mitológico), e há um tecido interdependente, interativo e retroativo entre o objeto de conhecimento e seu contexto, as partes e o todo, o todo e as partes, as partes entre si. Por isso a complexidade é a união entre a unidade e a multiplicidade (MORIN, 2001, p. 38-39).

A epistemologia complexa sustenta que a ética do humano deve ser pensada em movimento, via processo dinâmico de construção na articulação de macroconceitos nos processos formativos, como definiu Morin (2007). Esses impõem um "sistema-organização" de abertura oque referenda novos modos de pensar - complexa, que transformando a forma de ser e estar no mundo.

O processo formativo faz emergir formas globais ou sistemas organizativos compreendidos como produtos de inter-relação, de constelações conceituais, fora das quais se volatizam, desaparecem. Portanto, pensar a ética do humano, a partir da lógica complexa, exigiria pensara formação de professores via macroconceitos, como exemplo: pensar a sociedade exige (inter) relacioná-la com os conceitos de sujeito e cultura; pensar o macroconceito homem exige relacioná-lo à espécie/sociedade/cultura/história/subjetividade/ educação. Portanto, os socialismos, culturalismos, pedagogismos e psicologismos mostram-se expressões da precariedade teórica e conceitual porque geram esquemas simplificadores que dissolvem a complexidade da vida, e com ela também boa parte do que é humano.

Nessa ordem de pensamento, em acordo com a epistemologia complexa, restabelece-se o vínculo entre o saber e o dever, o que reconhece e realimenta a autonomia da ética na formação (MORIN, 2007). Esse vínculo se justifica, uma vez que a ciência precisa ser concebida juntamente com a ética e estar a serviço da solidariedade.

A antropologia complexa amplia a própria concepção de homem, que passa a ser concebida na tríade humana indivíduo-so- 
ciedade-espécie, resgatando o potencial humano, corpo e espírito, cérebro e mente, com todo o seu patrimônio hereditário, inato e adquirido, de natureza física, biológica, psíquica, social, cultural, mudando a forma como se estuda o homem em sociedade. Para a antropologia complexa, o homem é visto de uma maneira articulada, mergulhando suas raízes na emoção, no sentimento, na sensibilidade (BEHRENS, 2006).

Sim o sujeito complexo tem uma base (bio)lógica que corresponde a lógica própria do ser vivo, ele é um sistema, uma unidade e multiplicidade que a um só tempo é unidade múltipla. Como sistema vivo é aberto e fechado: aberto, pois necessita de informações novas do meio ambiente para continuar seu processo de amadurecimento, de crescimento e de desenvolvimento; fechado, pois necessita preservar sua identidade, singularidade e originalidade, seu modo de viver (MORIN, 1996, 2003). Entre estas duas noções - sistema aberto e fechado - há uma relação de antagonismo, de concorrência e de complementaridade, pois no sujeito complexo não há a exclusão da abertura do sistema vivo em detrimento de seu fechamento ou vice-versa. Entendido como sistema dependente do meio com o qual produz processos de troca, renovação e transformação, é autônomo que se abre e troca, renova-se e transforma-se na inter-relação com outros sistemas vivos. Quando se fecha, define assertivamente o que é seu e o que é dos outros (MORIN, 2007; 2003). Ao final, os sujeitos desenvolvem sua autonomia na dependência de sua cultura e vice-versa, nesse processo.

No caso do desenvolvimento da ética complexa, os sujeitos a constroem a partir de três fontes: interior, externa e anterior. A interior refere-se ao princípio de bondade inerente a cada pessoa; a externa é o aprendizado cultural, são as normas que aprendemos com aqueles com quem nos relacionamos (moral); a anterior diz respeito à fonte que nos é transmitida geneticamente, ela é determinante e está presente nos sujeitos como imperativo, mesmo que os sujeitos possam decidir acatar, obedecer ou não esse imperativo. Isso significa que os sujeitos nascem com uma carga genética própria, indi- 
vidual e única, que carrega em si todas as características da espécie humana que se revelam na individualidade de cada ser humano. Da mesma forma, as fontes éticas estão presentes em todos os indivíduos configurando o imperativo da ética. Essa se origina numa fonte interior, como injunção de um dever, que se associa e também provém de fonte externa - a cultura, pela injunção das crenças e normas que se somam à fonte genética originária. Se assim for, por que todos os sujeitos não são éticos?

É preciso lembrar que os sujeitos não formam um corpo homogêneo, ao contrário, sob múltiplas influências há um hiperdesenvolvimento do individualismo na atualidade e esse tem fortalecido o egocentrismo que enfraquece os fundamentos éticos. O individualismo tem desarticulado os vínculos entre sujeitos, espécie e sociedade. Desmoraliza, degrada a solidariedade. Por isso, Morin assevera:

[...] as fontes éticas quase não irrigam mais; a fonte individual é asfixiada pelo egocentrismo; a fonte comunitária é desidratada pela degradação da solidariedade; a fonte social é alterada pela compartimentalização, burocratização, atomização da realidade social e, além disso, é atingida por diversos tipos de corrupção; a fonte bioantropológica é enfraquecida pelo primado do individualismo sobre a espécie (MORIN, 2007, p. 28).

Morin (2007, p. 194, grifos nossos) afirmou que a ética complexa "[...] necessita daquilo que é mais individualizado no ser humano: a autonomia da consciência e o sentido da responsabilidade", ambas sustentam a ética da religação. Essa ética deve ser promovida e exercitada nos processos formativos para permitir a compreensão dos efeitos das ações de cada um.

$\mathrm{Na}$ interlocução da epistemologia complexa, antropologia complexa e a ética temos o sujeito ético que é formado pela: 1) auto ética, 2) socioética, e 3) antropoética. No caso da auto ética temos que provém de fonte interna equivalente à consciência do sujeito que desemboca ao mesmo tempo numa ética para o outro; a socioética provém de fonte externa, representa a ética da comunidade que a precede, a engloba e a transcende; é feita dessa relação entre o indivíduo 
uno e o outro múltiplo, precede e transcende a auto ética, posto que o indivíduo já nasce em uma comunidade de outros sujeitos. É inserida em uma cultura e em um contexto; a antropoética, de fonte anterior, é concernente à espécie humana, diz da organização dos seres vivos, é transmitida geneticamente; é a maneira ética da espécie de assumir seu destino humano no planeta. Essas bases da ética complexa são dimensões complementares e inseparáveis no sujeito complexo.

O desenvolvimento da auto ética no processo formativo prescinde de um trabalho constante de autoconhecimento, de auto elucidação e acima de tudo, de autocrítica. Ela é construída por meio da individualização da ética, na qual o sujeito é o próprio registro de seus valores, senhor de si mesmo, que se consolidam no processo de individuação, singularizam a sua existência como sujeito ético.

Segundo Morin (2005), no processo da construção do sujeito ético, atuam dois princípios: o da exclusão e o da inclusão. $\mathrm{O}$ princípio da exclusão faz o sujeito vivenciar o fato que ninguém pode ocupar o espaço egocêntrico do sujeito, princípio que exprime o "eu" individual; e o princípio da inclusão, que permite incluir o eu em um nós, pois rivaliza com o princípio de exclusão, e faz o sujeito sentir-se parte de uma coletividade. O princípio da inclusão transforma o "eu” em "nós", se expressa na forma de altruísmo, favorecendo atos eticamente desejáveis. Segundo essa ideia, o sujeito moral vive oscilando entre o caráter vital do egocentrismo e o potencial existente em cada sujeito para a prática do altruísmo.

$\mathrm{O}$ autor ainda apresenta dois eixos complementares da ética complexa: a socioética ou ética da comunidade e a antropoética. A socioética comporta normas de solidariedade, obediência às prescrições e tabus, amplia o entendimento de que os sujeitos pertencem a uma mesma sociedade, que são uma espécie que vive e depende do mesmo cosmos. Pensando em termos de complementaridade, ela nos faz pensar sobre a necessidade de que nossa atuação ajude na ênfase da religação, o que ocorre através da ética da solidariedade para com a espécie e para com a sociedade. A antropoética, por sua vez, diz especificamente de uma religação individual ao todo, impõe 
um ato moral que tem no disciplinar o egocentrismo e no desenvolvimento do altruísmo o maior valor da religação em amplo sentido. A antropoética é a ética em escala humana, com seu caráter trinário reativo ao circuito indivíduo/espécie/sociedade.

No que se refere à formação docente, a ética complexa auto ética, socioética e antropoética, amplia significativamente o entendimento da tríade indivíduo-sociedade-espécie o que suscita a ética da religação. Essa, por sua vez, faz com que os sujeitos reflitam sobre os efeitos de suas ações (ecologia da ação) em relação aos outros, à natureza e, muito particularmente, em relação ao seu patrimônio hereditário (inato e adquirido), sua natureza física, biológica, psíquica, social, cultural.

\section{Conclusão:}

\section{A formação ética de professores, a ética complexa e o processo de humanização.}

Trazer a ética complexa como base da formação ética de professores envolve à tomada de consciência da urgência de apoiarmos mudanças significativas no atual momento de nossa história. O destaque a formação ética de professores passa pela necessidade de proporcionar aos futuros professores a oportunidade para pensarem nas suas próprias concepções, levando-os a questionarem-se sobre os valores e princípios que professam e ensinam. A formação ética pode gerar autoconhecimento para que não ocorra o seu fechamento egocêntrico, futuramente de seus estudantes, durante sua formação, pois o professor é fundamental na composição da base dos valores e da abertura altruísta dos sujeitos.

A inspiração de Morin, da ética do humano e da religação pode remeter à ética da compreensão, da responsabilidade pessoal, do perdão, da arte de viver com sabedoria, da arte de religação com o outro, o que participa como fonte primordial para a edificação da consciência crítica necessária a uma pedagogia humanizadora. Nessa perspectiva, a interlocução entre a formação docente e a ética complexa pode favorecer forças que intensificam o processo de humanização. 


\section{Referências}

DELORS, Jacques. Educação: um tesouro a descobrir. Relatório para a UNESCO da Comissão Internacional sobre Educação para o século XXI. São Paulo: Cortez editora, 1998.

PADILHA, Henning, LEONI Maria. Sentido ético da formação: implicações escolares. EccoS Revista Científica, núm. 43, mao-agosto, 2017, pp. 85-95. Universidade Nove de Julho São Paulo, Brasil.

MARQUES, Mário Osório. Caminhos da formação de um educador. Coleção Mario Osório Marques. Ijuí, RS; Brasília, DF: Editora UNIJUÍ; INEP, 2006.

SEVERINO, Antonio Joaquim. Formação e atuação dos professores: dos seus fundamentos éticos. In: SEVERINO, Francisca Eleanora Santos. (Org.). Ética e formação de professores - política, responsabilidade e autoridade em questão. São Paulo: Cortez Editora, 2011, p. 130-149.

ALMEIDA, Cleide Rita S. de. Conviver com as incertezas. In: MAGALHÃES, Solange M. O.; SOUZA, Ruth Catarina Cerqueira R. de. Formação de professores elos da dimensão complexa e transdisciplinar. Goiânia: Liber Livro, 2012, p.143-158.

ALMEIDA, Melissa Rodrigues de; ABREU, Claudia Barcelos de Moura; ROSSLER, João Henrique. Contribuições de Vigotski para a análise da consciência de classe. Psicologia em Estudo, Maringá, v. 16, n. 4, 2011. p. 551-560.

BEHRENS, Marilda Aparecida. O paradigma da complexidade: metodologia de projetos, contratos didáticos e portfólios. Petrópolis: Vozes, 2006.

CAPRA, Fritjof. A teia da física: uma nova compreensão científica dos sistemas vivos. São Paulo: Cultrix, 1996.

CARVALHO, Edgar de Assis. Edgar Morin, a dialogia de um sapiens-demens. Revista Margem, São Paulo, n. 16, p. 167-170, dez. 2002.

FÁVERO, Maria Helena. A pesquisa de intervenção na construção de competências conceituais. Psicologia em Estudo, Maringá, v. 17, n. 1, 2013. p. 103-110.

FREIRE, Paulo. Pedagogia da autonomia. Rio de Janeiro: Paz e Terra, 1980.

HABERMAS, Jürgen. Conhecimento e interesse. Rio de Janeiro: Ed. Guanabara, 1987. 
HARGREAVES, Andy. A intensificação. O trabalho dos professores: melhor ou pior? In: . Os professores em tempo de mudança. O trabalho e a cultura dos professores na Idade Pós-Moderna. Alfragide. Portugal: McGraw-Hill de Portugal, 1999. p. 240-263.

JAPIASSU, Hilton Ferreira. Questões epistemológicas. Rio de Janeiro: Imago, 1981.

Introdução ao pensamento epistemológico. 4. ed. Rio de Janeiro: Francisco Alves, 1986.

MAGALHÃES, Solange Martins Oliveira. Ensino de Psicologia: limites o atual paradigma e a complementaridade do paradigma da complexidade. Educar em Revista, Curitiba, n. 48, p.265-287. jun. 2013.

MARX, Karl. Manuscritos econômico-filosóficos. São Paulo: Nova Cultural, 1987.

MOARES, Maria Cândida. O paradigma educacional emergente. 12. ed. Campinas: Papirus, 2007.

MORIN, Edgar. A noção de sujeito. In: SCHNITMAN, Dora Fried (Org.). Novos paradigmas, cultura e subjetividade. Porto Alegre: Artes Médicas, 1996. p. 45-59.

. Meus demônios. Rio de Janeiro: Bertrand Brasil, 1997.

Complexidade e transdisciplinaridade: a reforma da universidade e do ensino fundamental. Natal: Ed. UFRN, 1999.

Amor, poesia, sabedoria. Rio de Janeiro: Bertrand Brasil, 2001.

. O método 5: a humanidade da humanidade. Porto Alegre: Sulina, 2002.

A cabeça bem-feita: repensar a reforma, reformar o pensamento/Edgar Morin; tradução Eloá Jacobina. 8. Ed. Rio de Janeiro: Bertrand Brasil, 2003.

. O método 6: ética. Porto Alegre: Sulina, 2005.

. Introdução ao pensamento complexo. Porto Alegre, Sulina, 2007.

Os sete saberes necessários à educação do futuro. Trad. de Catarina Eleonora F. da Silva e Jeanne Sawaya. 2. ed. São Paulo: Cortez; Brasília, DF: Unesco, 2007.

MORIN, Edgar; CIURANA, Emílio-Roger; MOT'TA, Raúl Domingo. Educar na era planetária: o pensamento complexo como método de aprendizagem no erro e 
na incerteza humana. Trad. de Sandra Trabucco Valenzuela; revisão técnica da tradução Edgard de Assis Carvalho. 3. ed. São Paulo: Cortez; Brasília, DF: Unesco, 2009.

NICOLESCU, Basarab. A prática da transdisciplinaridade. In: Educação e transdisciplinaridade. UNESCO, 2000.

NEVES, Lúcia Maria Wanderley (Org.). A nova pedagogia da hegemonia: estratégias do capital para educar o consenso. São Paulo: Xamã, 2005.

PONCE, Branca Jurema; SAUL, Alexandre. A necessidade da estética e da ética no currículo escolar do século XXI. Psicologia da educação. São Paulo, n. 34, 2012. p. 6-19.

PRIGOGINE, Ilya. O fim das certezas: tempo, caos e as leis da natureza. São Paulo: Ed. Unesp, 2003.

RIOS, Terezinha Azeredo. Compreender e ensinar: por uma docência da melhor qualidade. 7. ed. São Paulo: Cortez, 2008.

. Ética na formação e no trabalho docente: para além de disciplinas e códigos. In: DALBEN, Ângela Imaculada Loureiro de Freitas et al. (Org.). Convergências e tensões no campo da formação e do trabalho docente. Belo Horizonte: Autêntica, 2010. p. 800-818.

ROGERS, Carl. Tornar-se pessoa. São Paulo: Martins Fontes, 1999.

SANTOS, Souza Boaventura de. Para uma sociologia das ausências e uma sociologia das emergências. Coimbra: Revista Crítica de Ciências Sociais, 63, out., 2002. Disponível em: < http://www.ces.uc.pt/myces/UserFiles/livros/71_Sociologia $\% 20$ das\%20ausencias_RCCS63.pdf>. Acesso em: março de 2020.

SCOCUGliA, Afonso Celso. A história das ideias de Paulo Freire e a atual crise de paradigmas. João Pessoa: Universitária, 1999.

SEVERINO, Antônio Joaquim. A busca do sentido da formação humana: tarefa da Filosofia da Educação. Educação e Pesquisa, São Paulo, v. 32, n. 3, p. 619634, dez. 2006.

Formação e atuação dos professores: dos seus fundamentos éticos. In: DALBEN, Ângela Imaculada Loureiro de Freitas et al. (Org.). Convergências e tensões no campo da formação e do trabalho docente. Belo Horizonte: Autêntica, 2010. p. 631-650.

. Formação e atuação dos professores: dos seus fundamentos éticos. In: SEVERINO, Antônio Joaquim; FERNANDES, Cleoni Maria Barbosa; SEVERINO, Francisca Eleadora Santos (Org.). Ética e formação de professores política, responsabilidade e autoridade em questão. São Paulo: Cortez, 2011.

VÁZQUEZ, Adolfo Sánchez. Ética. Trad. de João Dell'Anna. 28. ed. Rio de Janeiro: Civilização Brasileira, 2006. 